\section{СРАВНИТЕЛЬНЫЙ АНАЛИЗ И ХАРАКТЕРИСТИКА РАЗВИТИЯ СЕМЕЙНОГО БИЗНЕСА В ОБЛАСТЯХ КИТАЯ (ГОНКОНГ, МАКАО, ТАЙВАНЬ, МАТЕРИКОВЫЙ КИТАЙ)}

\section{THE COMPARATIVE ANALYSIS AND DEVELOPMENT FEATURES OF FAMILY BUSINESS IN REGIONS OF CHINA (HONG KONG, MACAU, TAIWAN, MAINLAND CHINA)}

Аннотация:

Статья посвящена актуальной проблеме значения и роли семейного бизнеса в современных условиях. В социально-экономической политике государств все больше внимания уделяется семье. В то же время недостаточно усилий прилагается для поддержки семейного бизнеса, хотя именно его развиmuе способно укрепить семейные связи, сделав экономически выгодной и значимой большую семью. Семейный бизнес также способен благоприятно повлиять на самозанятость населения, ускорить развитие небольших городов и деревень, удержать жителей от миграции в крупные города, повысить уровень доверия и нравственности в обществе и экономических отношениях. Рассмотрены характеристики развития семейного бизнеса в четырех областях Китая с разных позиций, точек зрения: старшее/младшее поколение, правительственная политика, законодательство, ситуация на внутреннем и внешнем рынках. Представленный опыт имеет особое значение для развития российского Дальнего Востока, находящегося ө условиях социально-экономической модернизации.

Ключевые слова:

семья, социальная политика, семейный бизнес, районы Китая, теория семейного предпринимательства, социально-экономическая модернизация.
Summary:

The paper deals with the relevant issue of the significance and role of family business in the modern world. The social and economic policy of states places a greater emphasis on the family. At the same time, family business suffers from the lack of support. However, its development strengthens family ties and makes a large family cost-effective and economically significant. Besides, family business can have a favorable impact on self-employment of the population, accelerate the development of small towns and villages, keep residents from migration to large cities, increase trust and morality in society and economic relations. The study examines the development features of family business in four regions of China from the standpoint of the older/younger generation, government policy, legislation, domestic and foreign markets situation. The research findings may be useful for developing the Russian Far East in the context of social and economic modernization.

Keywords

family, social policy, family business, regions of China, theory of family business, social and economic modernization.

Развитие теории семейного предпринимательства только начинается, данный феномен активно исследуется в настоящее время. Семейные отношения в гражданском обществе постоянно трансформируются под воздействием социальных, политических и демографических факторов. Современная семья как основа предпринимательских отношений представляет собой непрозрачную, закрытую хозяйственную систему. Именно по этой причине ни в зарубежной, ни в российской науке не представлено комплексное исследование семейного предпринимательства.

Семейное предпринимательство является специфической областью научных исследований, так как экономические отношения в нем тесно взаимосвязаны с социально-психологическими. Главным субъектом здесь выступает семья как социальная общность, формируемая узами родства, родительства, супружества, функционирующая согласно различным фрормальным и неформальным нормам.

Как отмечают А.А. Жук и К.М. Потий, «...ряд важных исследовательских задач, решение которых является необходимым условием повышения эффективности семейного бизнеса, в настоящее время даже не сформулирован российскими исследователями...» [1, с. 2901].

В России понятия семейного бизнеса и семейного предпринимательства не закреплены законодательно, отсутствуют их точные и полные определения. Это при том, что семейное предпринимательство во всем мире является одним из самых устойчивых направлений социального и экономического развития. В Российской Федерации темпы развития предпринимательства отстают от общемировых. Еще в июне 2016 г. был разработан проект федерального закона «О развитии семейного предпринимательства в РФ». Однако до сих пор на федеральном уровне не принята стратегия развития этого направления развития страны, не введены в научный оборот понятия семейного бизнеса и семейного предпринимательства. 
В связи с высокой изменчивостью факторов, воздействующих на состояние семейного предпринимательства, существует большое количество разнообразных комбинаций видовых признаков социально-экономических субъектов, которые следует отнести к семейному предпринимательству.

И.А. Плотникова определяет семейное предпринимательство как социально-институциональную форму малого бизнеса, представляющую собой определенным образом организованную систему экономической и трудовой деятельности, функционирующую в процессе социальных отношений между родственниками или членами одной семьи, которая объединяет значимые общественные ценности, целесообразно ориентированные стандарты и нормы поведения, удовлетворяющие потребностям общества [2, с. 13].

Исторически семейный бизнес выступал исходной точкой развития практически всех современных крупнейших компаний, и эта форма организации остается типичной для значительного числа крупных фрирм как в развитых, так и в развивающихся странах [3].

Полагаем, следует уделить особое внимание анализу развития семейных форм предпринимательства, представленных в азиатских государствах, прошедших непростой путь модернизации, в частности в Китайской Народной Республике.

Китайский опыт свидетельствует о важности поиска собственного пути развития. Неслучайно выражение «специфически китайский» сопровождает все фундаментальные фрормулировки, которыми в КНР определяют положение страны и ее политику. Подчеркнем: самобытность не исключает, но предполагает творческое использование чужого опыта. По формальным признакам Китай как раз наименее уникальная страна, поскольку его огромная территория и разнообразие внутренних условий не позволяют быть излишне специфичным. Опыт страны с огромным разнообразием хозяйственных условий, решившей задачу совмещения рынка и социализма, таким образом, имеет и некоторое универсальное значение.

Согласно докладу, подготовленному Исследовательским центром Всекитайской ассоциации промышленников и торговцев совместно с Университетом имени Сунь Ятсена, Чжэцзянским университетом и одной из самых известных семейных фрирм Сянгана - лидером по производству соусов и приправ «Ли Кум Ки», семейная форма предприятия довольно широко распространена в частном секторе китайской экономики. По итогам исследования 2010 г., до 55 \% всех действующих в Китае частных предприятий это семейные фирмы в узком смысле, в широком их доля превышает 85 \%. Самое большое количество семейных предприятий отмечается в Восточном Китае, а уровень их концентрации наиболее высок в обрабатывающей промышленности [4].

Суть китайских реформ может быть сведена к решительному отказу от всякого рода унификации. В Китае культивируется новое или хорошо забытое старое (индивидуальное, семейное, частное, смешанное, зарубежное, комбинированное в пространстве общественного). Государство выполняет роль арбитра и регулятора. Нагрузка на государство растет, ему приходится амортизировать социальные и региональные разрывы, нести ответственность за тяжелую экологическую ситуацию. В то же время нынешнее китайское руководство старается уйти от мелочного контроля над бизнесом, освобождая государство для решения ключевых аспектов развития. Задачей модернизации является синтез традиционного и современного.

Ниже представлена характеристика развития семейного предпринимательства по регионам Китая.

\section{Сянган (Гонконг)}

Среди 100 самых крупных предприятий семейного бизнеса, зарегистрированных на биржах, есть компании, основателям которых 80-90 лет, они самостоятельно создали и продолжают управлять компаниями. В некоторых компаниях уже четвертое поколение наследников управляет семейным бизнесом.

По сравнению с материковым Китаем у гонконгских предприятий семейного бизнеса модель управления ближе к европейской. Представители второго и третьего поколений руководителей предприятий семейного бизнеса обучались за рубежом, что обеспечило более высокую степень интернационализации и специализации образования.

Предприятия семейного бизнеса создают «семейные конторы» и «семейные комитеты» для управления, закрепляют в уставных документах управленческую структуру семейного бизнеса.

Сохраняются китайская культурная традиция и влияние конфуцианства: отец и старший брат имеют больший авторитет в управлении семейным бизнесом, старший сын становится преемником. Основатель предприятия, имеющий солидный возраст, все равно предпочитает работать или косвенно участвовать в управлении. Считается важным, чтобы была гармония между членами семьи и семейный бизнес оставался в руках семьи как можно дольше.

Предприятия семейного бизнеса уделяют большое внимание благотворительной деятельности. 
Первое поколение руководителей предприятий семейного бизнеса заинтересовано в передаче своим наследникам традиций участия в благотворительности. Такая заинтересованность не только способствует снижению социальной напряженности в обществе в целом, но и привлекает внимание членов семьи, не участвующих в семейном бизнесе, к деятельности предприятия.

Аомынь (Макао)

Экономика Аомыня базируется на игорном бизнесе. По данным «Отчета о структуре промышленности», опубликованного Управлением по статистике и всеобщему исследованию при администрации района Аомынь в 2013 г., 46,1 \% валового объема продукции приходится на казино, остальной объем распределен между отраслями, обслуживающими игорный бизнес и обеспечивающими его развитие: туризм, общественное питание, розничная торговля, транспорт, недвижимость, посредничество.

Аомынь, так же как и Сянган, был колонией. Но, несмотря на то что Аомынь начал товарный обмен со странами Азии, Европы и Америки еще в середине XVI в. и долгое время занимал лидирующие позиции в международной торговле, в конце XIX в. ведущая роль переходит к Сянгану. Второй подъем экономики Аомыня произошел после возращения его в состав Китая в 1999 г. за счет развития туризма и казино. За период 1999-2015 гг. ВBП (GDP) Аомыня увеличился в 5 раз. Экономическая стабильность этого периода обеспечила непрерывное развитие семейного бизнеса.

Большая часть предприятий Аомыня принадлежит четырем семьям. Остальные предприятия преимущественно малые, но также являются семейными. И в крупных, и в малых предприятиях бизнес передается третьему или даже четвертому поколению в семье.

Жители Аомыня отличаются сильной приверженностью к семье. Вместе с передачей семейного бизнеса происходит наследование семейных ценностей и идеалов. Считается, что семейные интересы важнее личных и находятся на первом месте. Мировоззрение большинства аомыньцев определяется такими жизненными целями, как жить для своего рода, прославить своих предков, своей славой приумножить славу своих прародителей. Поэтому по сравнению с Сянганом и Тайванем аомынские предприятия семейного бизнеса, особенно средние и малые, спокойнее передаются из поколения в поколение. Их руководители охотно уступают и идут на компромисс с тем, чтобы учесть интересы разных членов семьи. В случае возникновения конфрликтов они считают, что единство и солидарность семьи важнее прибыли. Некоторые руководители полагают, что предприятия семейного бизнеса - это всего лишь часть семейной истории, хроники, поэтому, когда предприятие попадает в кризис, появляются проблемы, они чаще всего выбирают семью и жертвуют предприятием, чтобы выгода предприятия не влияла на единство семейного рода.

Аомыньские предприниматели привязаны к своей малой родине, к людям, проживающим на этой территории, и поэтому при управлении бизнесом руководители стремятся получить не только прибыль, но и признание общества и уважение жителей. Дети аомыньских предпринимателей обладают сильным чувством долга перед своими родителями, охотно и легко принимают семейный бизнес от своих предков и поднимаются к новым вершинам. Именно поэтому в Аомыне очень редко семейный бизнес передается в чужие руки.

Благодаря длительному развитию семейного бизнеса в Аомыне у собственников бизнеса сформировался комплексный подход к подготовке преемников, в котором выделены следующие этапы:

1) воспитание и обучение преемника с детства при участии старшего поколения семейного предприятия;

2) практическая деятельность преемника на семейном или другом предприятии на исполнительских должностях;

3) совместное управление предприятием со старшим поколением;

4) постепенная передача полномочий по управлению бизнесом преемнику.

Тайвань

В отличие от предприятий материкового Китая, тайваньские предприятия семейного бизнеса имели первоначальный капитал. В конце гражданской войны 1945-1949 гг. с материкового Китая была вывезена крупная партия золота на остров Тайвань. Это была большая финансовая помощь для развития всего Тайваня, и в том числе для частного бизнеса. Также на Тайвань в то время выехала и часть трудоспособного населения, относившегося к высокообразованной интеллегенции. Эти люди в основном и стали создателями предприятий на том этапе.

Средний и малый бизнес является опорой экономики Тайваня. По данным Управления предприятий среднего и малого бизнеса при Министерстве экономики Тайваня, опубликованным в «Белой книге о среднем и малом бизнесе 2012 г.», количество предприятий среднего и малого бизнеса составляет 97,63 \% от всего количества предприятий Тайваня. Количество работающих на предприятиях среднего и малого бизнеса составляет 77,85 \% от всего занятого населения Тайваня. Большинство предприятий среднего и малого бизнеса являются семейными. 
В настоящее время на Тайване в большинстве случаев предприятиями семейного бизнеса управляет второе поколение семьи. Эти руководители поддерживают тенденции развития международной экономики. Они осознают проблемы в области защиты окружающей среды и вызванные кризисом научных технологий. Они уделяют большое внимание инновационным продуктам, инновационным технологиям в сфрере реализации товаров и в области управления и т. д. Также они понимают, что необходимо учитывать интересы партнеров, прямых и косвенных участников бизнеса: клиентов, инвесторов, поставщиков, сотрудников и др.

Тайвань раньше материкового Китая начал заниматься проблемами социальной ответственности бизнеса. К настоящему времени правительство Тайваня приняло законодательные акты и контролирует их исполнение, создавая условия для эффективной деятельности предприятий и проявления социальной ответственности. Тайваньское правительство и уполномоченные органы требуют от предприятий сферы финансов и банковского дела, продовольственной отрасли и нефтехимической промышленности, от крупных предприятий, работающих на фрондовом рынке, подавать «Отчет о социальной ответственности предприятий».

В 1966 г. Комитет международного экономического сотрудничества Исполнительной палаты Тайваня создал целевую группу по консультированию предприятий среднего и малого бизнеса. Эта целевая группа функционирует и в настоящее время. Также активно создаются отраслевые структуры и ассоциации, содействующие развитию среднего и малого бизнеса. Они играют роль посредника между правительством и предприятиями среднего и малого бизнеса и могут помочь предприятиям в преодолении трудностей, когда те сталкиваются с нехваткой финансирования, отсутствием кадров и другими проблемами.

В 2006 г. создана «Межотраслевая коммуникативная ассоциация второго поколения семейного бизнеса г. Тайчжун». В рамках этой ассоциации предприятия среднего и малого бизнеса разных отраслей могут интегрировать ресурсы, делиться ценной информацией, создавать полезные межличностные контакты между представителями второго поколения семейного бизнеса.

Участники ассоциации должны соответствовать следующим требованиям: являться представителями второго поколения семейного бизнеса и уже работать на семейном предприятии. Ассоциация объединяет преемников, управляющих предприятиями разных отраслей, что способствует обмену информацией и раскрытию потенциала предприятий семейного бизнеса.

\section{Материковый Китай}

В материковом Китае развитие семейного бизнеса началось гораздо позднее, чем в Сянгане, Аомыне и Тайване. Это произошло после экономических реформ 1978 г. Сейчас большинство предприятий семейного бизнеса находится в процессе передачи бизнеса от первого поколения ко второму.

Из-за того, что до 2016 г. существовали ограничения по количеству детей в семье - «Одна семья - один ребенок», в настоящее время существует проблема при передаче семейного бизнеса. По данным журнала Forbes за 2014 г., среди 747 предприятий на биржевом рынке, которые принимали участие в исследовании, 90,1 \% основателей все еще занимаются управлением компаний и только в 74 (9,9 \%) предприятиях второе поколение перешло на управляющий пост. Представители первого и второго поколений одновременно работают в своей компании в 37,6 \% предприятий, среди них 55 \% предприятий, в управлении которых участвует единственный преемник [5].

Численность населения оказывает большое влияние на преемственность в передаче семейного бизнеса в Китае. Большинство создателей семейного бизнеса в Китае принадлежат к возрастной категории 60-70 лет, они заинтересованы в передаче управления бизнесом второму поколению, а третье поколение находится на стадии воспитания и подготовки. У поколения создателей семейного бизнеса в семьях были сестры и братья, в среднем 3-4 ребенка в семье. У второго поколения - один ребенок. Третьему поколению разрешили иметь двух детей. Полагаем, что в недалеком будущем ограничение по количеству детей в семье будет полностью снято. Таким образом, появится возможность передачи семейного бизнеса через поколение, минуя поколение «единственного ребенка в семье».

По китайской традиции преемником должен быть сын, преимущество имеет старший сын. Когда старший сын не способен управлять или умер, очередь переходит ко второму сыну, и т. д. Но в настоящее время в Китае сложилась ситуация, когда многие наследники семейного бизнеса - женщины. Это связано с тем, что у многих создателей предприятий есть только один ребенок, и этот единственный наследник - дочь. Создатели предприятий семейного бизнеса смирились с этим и передают власть дочери в надежде на то, что хороший зять поможет развивать семейный бизнес.

Создатели семейного бизнеса считают, что компании, созданные их руками, - это тоже их дети. Они испытывают огромное чувство ответственности за них и надеются, что компания всегда будет под управлением и контролем членов их семьи. 
Современный рынок профрессиональных менеджеров еще не развит, поэтому создателям семейного бизнеса в Китае остается два пути для продолжения существования бизнеса: передать наследникам или продать свой бизнес. Однако, если говорить о семейном предприятии как о специфической форме бизнеса, существует только один путь, чтобы сохранить непрерывное управление и контроль в рамках семьи, - передача бизнеса по наследству.

Сейчас в Китае законодательство в сфрере предпринимательства несовершенно, политика в области защиты предпринимательства неэффективна, а поддержка средних и малых предприятий недостаточна. Поэтому предприятия семейного бизнеса не могут быстро развиваться. Необходимо наладить отношения с государственными органами, различными инспекциями.

В 2018 г. исполнилось 5 лет с момента начала реализации концепции «Один пояс, один путь». В рамках этой концепции Китай подписал договоры о совместном сотрудничестве уже более чем с 40 государствами и международными организациями. Следуя данной концепции в развитии экономики, Китай даст возможность семейным предприятиям развиваться не только на внутреннем, но и на международном рынке.

В рефоомируемой России социологические данные говорят о кризисе семьи. Это неизбежно сказывается на малом и среднем бизнесе, поскольку до сих пор значительная часть малого бизнеса начинается при финансовой и трудовой поддержке родственников. Семья в современной России все реже дает моральную, финансовую и трудовую поддержку в бизнес-начинаниях, что наряду с неудовлетворительной поддержкой малого бизнеса государством не позволяет достичь экономического развития через процветание малых предприятий. Это особенно ярко проявляется в российском сельском хозяйстве, где роль семейного бизнеса совершенно несравнима с мировой ситуацией. В современной России необходимо развивать семейный бизнес, учитывая опыт как русской истории, так и современных семейных компаний за рубежом. Нужна целенаправленная социальная политика правительства по возрождению семейного бизнеса [6].

Особенно важно учитывать эти подходы при реализации программ развития Дальнего Востока России, в частности таких как «дальневосточный гектар», создание зон опережающего экономического развития.

\section{Ссылки:}

1. Жук А.А., Потий К.М. Феномен семейного предпринимательства в современной экономической теории // Российское предпринимательство. 2017. Т. 18, № 19. С. 2891-2908. https://doi.org/10.18334/rp.18.19.38321.

2. Плотникова И.А. Институциональное развитие семейных предприятий в сфере малого бизнеса (на примере Пензенской области) : дис. ... канд. социол. наук. Пенза, 2015. 247 с.

3. Шило П., Корчагина Е. Специфика семейного бизнеса в контексте организационной культуры фрирмы // Проблемы теории и практики управления. 2016. № 2. С. 136-137.

4. В Китае вышел первый доклад, посвященный семейным предприятиям страны [Электронный ресурс] // Жэньминь Жибао. 2011. 13 дек. URL: http://russian.people.com.cn/31518/7674984.html (дата обращения: 04.02.2019).

5. 中国家族企业传承报告/一北京: 中信出版社, $2015.11=$ Доклад о преемственности предприятий семейного бизнеса в Китае. Пекин, 2015.

6. Важенина И.С., Важенин С.Г., Сухих В.В. Поддержка семейного бизнеса - стратегический ресурс эффективной социально-экономической политики и восстановления доверия в экономике // Динамика и инерционность воспроизводства населения и замещения поколений в России и СНГ: VII Уральский демографический форум с международным участием : сб. ст. Т. 1: Социология и история воспроизводства населения России. Екатеринбург, 2016. С. 347-354.

\section{References:}

'In China the First Report on Family Enterprises of the Country is Published' 2011, Zhenmin Zhibao, Dec. 13, viewed 10 February 2019, <http://russian.people.com.cn/31518/7674984.html>, (in Russian).

Plotnikova, IA 2015, Institutional Development of Family Enterprises in the Field of Small Business (on the Example of the Penza Region), PhD thesis, 247 p., (in Russian).

Report on the Succession of Family Business Enterprises in China 2015, Beijing, (in Chiness).

Shilo, P \& Korchagina, E 2016, 'Specificity of the Family Business in the Context of the Organizational Culture of the Company', Problemy teorii i praktiki upravleniya, no. 2, pp. 136-137, (in Russian).

Vazhenina, IS, Vazhenin, SG \& Sukhikh, VV 2016, 'Family Business Support is a Strategic Resource of Effective SocioEconomic Policy and Restoration of Trust in the Economy', Dinamika $i$ inertsionnost' vosproizvodstva naseleniya $i$ zameshcheniya pokoleniy v Rossii i SNG: VII Ural'skiy demograficheskiy forum s mezhdunarodnym uchastiyem: sb. st. T. 1: Sotsiologiya $i$ istoriya vosproizvodstva naseleniya Rossii, Yekaterinburg, pp. 347-354, (in Russian).

Zhuk, AA \& Potiy, KM 2017, 'The Phenomenon of Family Entrepreneurship in Modern Economic Theory', Rossiyskoye predprinimatel'stvo, vol. 18, no. 19, pp. 2891-2908, https://doi.org/10.18334/rp.18.19.38321, (in Russian) 